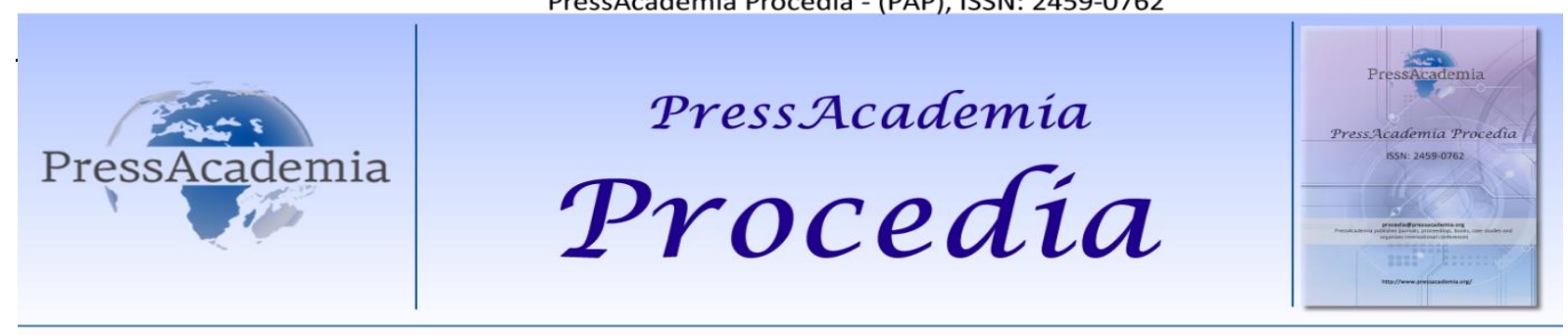

Global Business Research Congress (GBRC), May 24-25, 2017, Istanbul, Turkey.

\title{
EXAMINING RELATIONSHIP BETWEEN COMPOSITE LEADING INDICATORS AND BORSA ISTANBUL SECTOR INDICES
}

\section{DOI: 10.17261/Pressacademia.2017.666 \\ PAP-GBRC-V.3-2017(93)-p.860-866}

\section{Sinem Eyuboglu ${ }^{1}$, Kemal Eyuboglu $^{2}$}

${ }^{1}$ Karadeniz Technical University, Department of Econometrics, Trabzon, Turkey. sinemyilmaz@ktu.edu.tr

${ }^{2}$ Karadeniz Technical University, Department of Business Administration, Trabzon, Turkey. keyuboglu@ktu.edu.tr

To cite this document

Eyuboglu, S. and K. Eyuboglu, (2017).Examining relationship between composite leading indicators and Borsa Istanbul sector indices, PressAcademia Procedia (PAP), V.3, p.860-866.

Permemant link to this document: $\underline{\text { http://doi.org/10.17261/Pressacademia.2017.666 }}$

Copyright: Published by PressAcademia and limited licenced re-use rights only.

\section{ABSTRACT}

The prediction of fluctuations in economic activity has become even more important, especially after the crises experienced in recent years. In order to make such a prediction, economic and financial indicators are needed. The Composite Leading Indicators (BONC) published by Central Bank of the Republic of Turkey is useful in predicting the macroeconomic contraction or expansion. In this study, it is tested whether there is a relationship between Composite Leading Indicators Index and 12 Borsa Istanbul sector indices returns. Unit root test results show that sector indices are stationary at the first differences and the BONC is at level. Thus long term relationship between each sector indices and the BONC is examined by Boundary Test. The findings show that there is a long term and relationship between BONC and all the sector indices in the study. Also it has been determined that positive change in the BONC has a statistically significant and positive effect on XUTEK and XGMYO in the long term. The short term relationship is also found between all sector indices and BONC. In addition, it is determined that increase in BONC affects all sector indices positively in the short term. These results indicated that investors take into account the BONC without distinguishing the sector when investing to stocks and that BONC is an important indicator for stock returns.

Keywords: Composite leading indicators, Borsa Istanbul, bound test, ARDL models, sector indices.

JEL Codes: E44, G10

\section{BíLEŞiK ÖNCÜ GÖSTERGELER ILE BORSA ISTANBUL SEKTÖR ENDEKSLERI ARASINDAKI iLIŞKINININ INCELENMESi}

\section{ÖZET}

Ekonomik faaliyetlerdeki dalgalanmaların önceden tahmin edilebilmesi, özellikle de son yıllarda yaşanan krizlerden sonra daha da önemli hale gelmiştir. Bu tür bir tahminin yapılabilmesi için ise ekonomik ve finansal göstergelere ihtiyaç duyulmaktadır. TCMB'nin yayınladığı bileşik öncü göstergeler (BONC) makroekonomide yaşanılan daralmaların veya genişlemelerin önceden tahmini açısından yararlıdır. Bu çalışmada 12 Borsa İstanbul sektör ile BONC arasında ilişki olup olmadığı araştırılmıştır. Birim kök testi sonuçları sektör endekslerinin düzeyde, BONC'un ise 1. farkında durağan olduğunu ortaya koymuştur. Bu açıdan sektör endeksleri ile BONC arasındaki uzun dönem ilişki Sınır Testi yardımıyla araştırılmıştır. Elde edilen bulgular her bir sektör endeksinin BONC ile uzun dönemde ilişkili olduğunu göstermiştir. İlaveten uzun dönemde BONC'ta meydana gelen yükselişin, XUTEK ve XGMYO endekslerini istatistiksel açıdan anlamlı ve pozitif yönde etkilediği belirlenmiştir. Kısa dönemde de tüm sektör endeksleri ile BONC arasında bir ilişki olduğu saptanmıştır. Ayrıca BONC'taki artışın tüm sektör endekslerini kısa dönemde pozitif yönde etkilediği de tespit edilmiştir. BONC ile sektör endeksleri arasındaki ilişkilere ait bu sonuçlar, yatırımcıların hisse senetlerine yatırım yaparken sektör ayırt etmeksizin BONC'u dikkate aldığını ve BONC'un hisse senedi getirileri için önemli bir gösterge olduğunu ortaya koymaktadır.

Anahtar Kelimeler: Bileşik öncü göstergeler, Borsa İstanbul, sınır testi, ARDL modelleri, sektör endeksleri.

JEL Kodları: E44, G10 


\section{GíRiş}

Özellikle son yıllarda yaşanan krizler ve belirsizlikler ekonomik faaliyetlerin yavaşlamasına ve dolayısıyla varlık fiyatlarında oynaklığa neden olmaktadır. Bu açıdan ekonomik faaliyetlerdeki büyüme ve daralmaların önceden görülebilmesi hem politika yapıcılar hem de piyasa oyuncuları açısından önem arz etmektedir. Bu amaçla OECD, ülkelerdeki ekonomik faaliyetlerdeki değişimlerin erken sinyallerini vermek amacıyla 1970'lerde bileşik öncü göstergeler sistemini geliştirmiştir.

Türkiye'de de 2002 yılında TCMB, OECD ile yürüttüğü ortak çalışma sonucunda Türkiye ekonomisindeki dalgalanmaları önceden belirleyebilmek amacıyla bileşik öncü göstergeler endeksi oluşturmuştur. Oluşturulan bu endeks, Aralık 2002 tarihinden bu yana aylık olarak OECD ve TCMB internet sayfalarında yayınlanmaktadır (Demirhan, 2014: 2). Bu göstergenin sunduğu bilgiler, ekonomistler, iş adamları ve politika yapıcılar için mevcut ve kısa dönemdeki ekonomik durumun zamansal analizi açısından oldukça büyük önem arz etmektedir (Topçu, 2014: 168).

Bu çalışmada Borsa İstanbul'da (BIST) işlem gören hisse senetlerinin oluşturduğu 12 sektör endeksi (XUSIN, XTEKS, XKAGT, XKMYA, XMANA, XMESY, XULAS, XTRZM, XBANK, XSGRT, XGMYO, XUTEK) ile bileşik öncü göstergeler endeksi (BONC) arasında kısa ve uzun dönemde ilişki olup olmadığı araştırılmıştır.

\section{LITERATÜR INCELEMESi}

Literatürde BONC ile menkul kıymet borsaları arasındaki ilişkinin inceleyen çalışmalarda; Hacıhasanoğlu ve Soytaş (2011) 2001-2010 dönemi için yapmış oldukları çalışmalarında bileşik öncü göstergeler ile mali, hizmetler, savunma, sınai, teknoloji ve ulaştırma endeksleri arasındaki ilişkiyi incelemişlerdir. Yapılan analizler sonucunda uzun dönemde bileşik öncü göstergelerde meydana gelen pozitif değişimlerin, savunma ve hizmet sektörleri dışında, tüm sektörlerini olumlu etkilediği belirlenmiştir. Makroekonomide meydana gelen kısa süreli şokların ise tüm endeksleri başta pozitif etkilediği ama bu etkinin bir yıl içinde ortadan kaybolduğu belirlenmiştir.

Gülhan vd. (2012) ise 2000-2010 dönemi için bileşik öncü göstergeler ve borsa endeksleri arasındaki ilişkiyi uluslararası boyutta araştırmışlardır. Çalışmada dokuz Avrupa ülkesi (İngiltere, İspanya, Hollanda, İtalya, Almanya, Fransa, Belçika, Avusturya, Türkiye), beş Asya ülkesi (G. Kore, Japonya, Endonezya, Hindistan, Çin), dört Amerika Kıtası ülkesi (ABD, Kanada, Meksika, Brezilya) olmak üzere 18 ülkeye ilişkin veriler kullanılmıştır. Yapılan analizler sonucunda Almanya hariç diğer çalışmada yer alan ülkelerde bileşik öncü göstergelerin borsalar endeksi üzerinde anlamlı etkisinin bulunduğu ve bu iki değişkenin eşbütünleşik olduğu saptanmıştır.

Topcu ve Ünlü (2013) 2000-2011 dönemi için gelişmekte olan 13 ülkeye (Brezilya, Şili, Çin, Çek Cumhuriyeti, Macaristan, Hindistan, Endonezya, G.Kore, Meksika, Polonya, Rusya, Güney Afrika ve Türkiye) ilişkin verileri kullanarak bileşik öncü göstergelerle hisse senedi fiyatları arasındaki uzun dönem ilişkiyi ve nedensellik ilişkisini test etmişlerdir. Çalışma sonucunda ise, bileşik öncü göstergeler ile borsa arasında bir eşbütünleşme ilişkisi belirlenememiştir. İlaveten 2 değişken arasında çift yönlü bir nedensellik ilişkisinin olduğu ifade edilmiştir.

Topcu (2014) 2011-2014 dönemi için BIST-100 ile bileşik öncü göstergeler ile hisse senedi fiyatları arasındaki eşbütünleşme ve nedensellik ilişkisini araştırmıştır. Yapılana analizler sonucunda elde edilen bulgular öncü göstergeler ile hisse senedi piyasası arasında uzun dönemli bir ilişki bulunmadığını; kısa dönemde ise öncü göstergelerden hisse senedi piyasasına doğru tek yönlü bir nedensellik ilişkisinin bulunduğunu göstermiştir.

\section{VERI VE YÖNTEM}

Aylık verilerin kullanıldığı bu çalışmada örneklem dönemi 2006:01-2016:10 tarihlerini kapsamaktadır. Çalışmada kullanılan çalışmada yer alan Bileşik Öncü Göstergeler verileri TCMB Elektronik Veri Dağıtım Sisteminden ve Borsa İstanbul endekslerine ilişkin veriler ise Borsa İstanbul'dan elde edilmiştir. Tablo 1'de analizlerde kullanılan sektör endeksleri gösterilmiştir.

Tablo 1: Çalışmada Yer Alan Endeksler

\begin{tabular}{|c|c|c|c|}
\hline Kodu & Endeks Adı & Kodu & Endeks Adı \\
\hline XUSIN & BIST Sınai & XULAS & BIST Ulaştırma \\
\hline XTEKS & BIST Tekstil ve Deri & XTRZM & BIST Turizm \\
\hline XKAGT & BIST Orman Kâğıt Basım & XBANK & BIST Banka \\
\hline XKMYA & BIST Kimya Petrol Plastik & XSGRT & BIST Sigorta \\
\hline XMANA & BIST Metal Ana & XGMYO & BISTYO \\
\hline XMESY & BIST Metal Eşya Makine & XUTEK & BIST Teknoloji \\
\hline
\end{tabular}


Çalışmada endekslere ilişkin getiriler hesaplanmıştır. Getiri hesaplanmasında;

$R_{t}=\ln \left(\frac{P_{t}}{P_{t-1}}\right)$

formülünden yararlanılmıştır. Burada $R_{t}$; ilgili endeksin $t$ dönemi doğal logaritmik getiri değerini, $P_{t}$; ilgili endeksin $t$ dönemi kapanış değerini ve $\mathrm{P}_{\mathrm{t}-1}$; ilgili endeksin $\mathrm{t}-1$ dönemindeki kapanış değerini göstermektedir.

Analizin ilk aşamasında, değişkenlerin durağan oldukları seviyeler Genişletilmiş Dickey-Fuller (ADF) ve Phillips-Perron (PP) birim kök testleri yardımıyla tespit edilmiştir. Gecikme uzunlukları ise AIC kriteri ile belirlenmiştir. Değişkenlerin farklı seviyelerde durağan olması durumunda ise değişkenler arasındaki uzun dönemli ilişkinin incelenmesi Pesaran vd. (2001) tarafından ortaya konan Sınır Testi yöntemi ile araştırımıştır.

Değişkenler arasında eş bütünleşme ilişkisi tespit edildikten sonra uzun ve kısa dönem ilişkileri belirlemek için ARDL modelleri kullanılmıştır.

Farklı seviyede durağan olduğu belirlenen değişkenler arasındaki nedensellik ilişkisi ise aynı seviyeden durağan olmayan değişkenlerde nedensellik ilişkisinin araştırı masını sağlayan Toda ve Yamamoto (1995) nedensellik testi ile incelenmiştir.

\section{BULGULAR VE TARTIŞMA}

Tablo 2'de çalışmada yer alan BONC'a ve 12 Borsa İstanbul sektör endeksine ilişkin tanımlayıcı istatistikler verilmiştir.

Tablo 2: Tanımlayıcı İstatistikler

\begin{tabular}{|c|c|c|c|c|c|c|}
\hline & Ortalama & Maksimum & Minimum & St. Sapma & Carpıklık & Basıklık \\
\hline LBONC & 5,312 & 5,491 & 5,11 & 0,114 & $-0,11$ & 1,68 \\
\hline LXUSIN & 0,007 & 0,192 & $-0,25$ & 0,062 & $-0,97$ & 6,47 \\
\hline LXTEKS & 0,007 & 0,198 & $-0,26$ & 0,076 & $-0,61$ & 4,38 \\
\hline LXKAGT & 0,001 & 0,271 & $-0,28$ & 0,083 & $-0,16$ & 5,11 \\
\hline LXKMYA & 0,007 & 0,228 & $-0,25$ & 0,070 & $-0,56$ & 5,41 \\
\hline LXMANA & 0,009 & 0,317 & $-0,34$ & 0,088 & $-0,28$ & 5,33 \\
\hline LXMESY & 0,010 & 0,234 & $-0,38$ & 0,086 & $-1,04$ & 6,46 \\
\hline LXULAS & 0,011 & 0,244 & $-0,37$ & 0,103 & $-0,37$ & 3,96 \\
\hline LXTRZM & $-0,005$ & 0,248 & $-0,32$ & 0,089 & $-0,62$ & 4,87 \\
\hline LXBANK & 0,004 & 0,229 & $-0,26$ & 0,085 & $-0,20$ & 3,79 \\
\hline LXSGRT & 0,006 & 0,298 & $-0,41$ & 0,093 & $-1,04$ & 8,12 \\
\hline LXGMYO & 0,001 & 0,192 & $-0,38$ & 0,084 & $-1,17$ & 6,84 \\
\hline LXUTEK & 0,011 & 0,213 & $-0,28$ & 0,084 & $-0,38$ & 4,04 \\
\hline
\end{tabular}

Tabloya göre ilgili dönem boyunca BIST Turizm hariç diğer tüm endekslerin yatırımcılarına pozitif ortalama getiriler sağladığı belirlenmiştir. Oynaklık açısından sektör endeksleri arasından en yüksek oynaklığa sahip olan endeksin BIST Ulaştırma; en düşük oynaklığa sahip olan endeksin ise BIST Sınai olduğu görülmektedir.

Eş bütünleşme analizine geçilmeden önce ADF ve PP birim kök testleri yardımıyla değişkenlerin durağan oldukları düzeyler belirlenmiştir. Tablo 3'te BONC ve Borsa İstanbul sektör endeksleri için hesaplanan ADF ve PP birim kök testi sonuçları görülmektedir. Buna göre çalışmada kullanılan borsa sektör endekslerinin \%1 önem düzeyinde seviye değerlerinde, BONC değişkeninin ise \%1 önem düzeyinde birinci farkında durağan olduğu gözlenmiştir. Bu açıdan çalışmada BONC ile BIST endeksleri arasındaki eş bütünleşme ilişkisi Sınır Testi yöntemi ile incelenmiştir.

Tablo 3: Değişkenlere Ait Birim Kök Sonuçları

\begin{tabular}{|c|c|c|c|c|}
\hline \multirow{2}{*}{ Değişkenler } & \multicolumn{2}{|c|}{ ADF } & \multicolumn{2}{|c|}{ PP } \\
\hline & Sabit & Sabit & Sabit & Sabit \\
\hline LBONC & $-0,961$ & $-2,652$ & $-0,815$ & -2.504 \\
\hline$\triangle$ LBONC & $-4,261^{a}$ & $-4,208^{a}$ & $-3,233^{a}$ & $-3,242^{a}$ \\
\hline LXUSIN & $-9.442^{a}$ & $-9.389^{a}$ & $-9.736^{\mathrm{a}}$ & $-9.877^{\mathrm{a}}$ \\
\hline LXTEKS & $-9.775^{a}$ & $-9.558^{a}$ & $-9.881^{\mathrm{a}}$ & $-9.139^{a}$ \\
\hline LXKAGT & $-11.799^{a}$ & $-11.131^{a}$ & $-11.711^{a}$ & $-11.711^{a}$ \\
\hline LXKMYA & $-10.470^{a}$ & $-10.488^{a}$ & $-10.550^{\mathrm{a}}$ & $-10.590^{a}$ \\
\hline LXMANA & $-11.083^{a}$ & $-11.910^{a}$ & $-9.222^{\mathrm{a}}$ & $-9.922^{a}$ \\
\hline LXMESY & $-8.666^{a}$ & $-8.443^{a}$ & $-8.811^{a}$ & $-8.122^{a}$ \\
\hline LXTRZM & $-10.301^{a}$ & $-10.321^{a}$ & $-10.368^{a}$ & $-10.388^{a}$ \\
\hline
\end{tabular}




\begin{tabular}{|c|c|c|c|c|}
\hline LXULAS & $-9.295^{\mathrm{a}}$ & $-9.913^{a}$ & $-8.699^{a}$ & $-9.591^{a}$ \\
\hline LXBANK & $-10.504^{a}$ & $-10.533^{a}$ & $-10.523^{a}$ & $-10.533^{a}$ \\
\hline LXSGRT & $-11.117^{a}$ & $-11.655^{a}$ & $-11.221^{a}$ & $-11.772^{a}$ \\
\hline LXGMYO & $-9.123^{a}$ & $-9.068^{a}$ & $-9.246^{a}$ & $-9.199^{a}$ \\
\hline LXUTEK & $-10.134^{a}$ & $-10.633^{a}$ & $-10.331^{a}$ & $-10.073^{a}$ \\
\hline
\end{tabular}

a, \%1 anlamlılık düzeyini göstermektedir.

\subsection{Eş Bütünleşme Testi}

Bu aşamada BONC ile BIST sektör endeksleri arasındaki uzun dönem ilişkinin araştırılması için Sınır Testi uygulanmış ve sonuçları Tablo 4'te gösterilmiştir. Buna göre Tablo 4'te görüldüğü üzere tüm modeller için hesaplanan F istatistiği Pesaran vd. (2001) tarafından \%1 için belirlenen kritik değerlerden yüksek olduğundan eş bütünleşme ilişkisinin olmadığına dayanan hipotez reddedilmiştir. Değişkenler arasında eş bütünleşme ilişkisi tespit edildiğinden uzun ve kısa dönem ilişkileri belirlemek için ARDL modellerine geçilmiştir.

Tablo 4: Sınır Testi Sonuçları

\begin{tabular}{|c|c|c|c|}
\hline \multicolumn{4}{|c|}{ LBONC (Bağımsı Değişken) } \\
\hline Bağımlı Değişken & F istatistiği Değeri & Bağımlı Değişken & F istatistiği Değeri $^{\text {aš }}$ \\
\hline LXUSıN & $49,811^{\mathrm{a}}$ & LXULAS & $33,963^{\mathrm{a}}$ \\
\hline LXTEKS & $40,295^{\mathrm{a}}$ & LXTRZM & $32,102^{\mathrm{a}}$ \\
\hline LXKAGT & $51,998^{\mathrm{a}}$ & LXBANK & $48,661^{\mathrm{a}}$ \\
\hline LXKMYA & $37,182^{\mathrm{a}}$ & LXSGRT & $48,812^{\mathrm{a}}$ \\
\hline LXMANA & $35,946^{\mathrm{a}}$ & LXGMYO $^{\mathrm{a}}$ & $47,338^{\mathrm{a}}$ \\
\hline LXMESY & $46,848^{\mathrm{a}}$ & LXUTEK & $48,466^{\mathrm{a}}$ \\
\hline
\end{tabular}

\%1 anlamlılık düzeyini göstermektedir.

ARDL Modellerinde gecikme uzunlukları AIC kriterine göre belirlenmiştir. Tablo 5'te değişkenler için hesaplanan ARDL Modelleri tahmin sonuçları sunulmuştur.

Tablo 5: Değişkenler için Hesaplanan ARDL Modeli Tahmin Sonuçları

\begin{tabular}{|c|c|c|c|c|c|c|c|}
\hline Değişkenler & Model & Katsayı & $\mathrm{t}$ istatistiği & Değişkenler & Model & Katsayı & t istatistiği \\
\hline $\operatorname{LXUSIN}(-1)$ & \multirow{4}{*}{$\operatorname{ARDL}(1,1)$} & -0.050 & -0.582 & LXTEKS(-1) & \multirow{4}{*}{$\operatorname{ARDL}(1,1)$} & 0.034 & 0.390 \\
\hline LBONC & & 1.328 & $5.884^{\mathrm{a}}$ & LBONC & & 1.140 & $4.561^{\mathrm{a}}$ \\
\hline LBONC (-1) & & -1.281 & $-5.871^{a}$ & LBONC (-1) & & -1.104 & $-4.555^{a}$ \\
\hline C & & -0.264 & -1.155 & c & & -0.205 & -0.701 \\
\hline \multicolumn{4}{|c|}{$\mathrm{R}^{2}=0.235 \quad$ White $=1.313 \quad \mathrm{LM}(1)=0.535 \quad \mathrm{LM}(12)=1.107$} & \multicolumn{4}{|c|}{$\mathrm{R}^{2}=0.133$ White $=0,496 \mathrm{LM}(1)=0.476 \mathrm{LM}(12)=1.185$} \\
\hline Değişkenler & Model & Katsayı & $t$ istatistiği & Değişkenler & Model & Katsayı & t istatistiği \\
\hline LXKAGT(-1) & \multirow{4}{*}{$\operatorname{ARDL}(1,1)$} & -0.156 & $-1.791^{c}$ & LXKMYA(-1) & \multirow{4}{*}{$\operatorname{ARDL}(1,1)$} & -0.084 & -0.975 \\
\hline LBONC & & 1.265 & $4.290^{\mathrm{a}}$ & LBONC & & 1.391 & $5.192^{\mathrm{a}}$ \\
\hline $\operatorname{LBONC}(-1)$ & & -1.187 & $-4.263^{\mathrm{a}}$ & $\operatorname{LBONC}(-1)$ & & -1.331 & $-5.173^{\mathrm{a}}$ \\
\hline C & & -0.436 & -1.333 & $\mathrm{C}$ & & -0.335 & -1.249 \\
\hline \multicolumn{4}{|c|}{$\mathrm{R}^{2}=0.109 \quad$ White $=0.749 \quad \mathrm{LM}(1)=0.110 \quad \mathrm{LM}(12)=0.896$} & \multicolumn{4}{|c|}{$\mathrm{R}^{2}=0.184$ White $=1.144 \mathrm{LM}(1)=0.436 \mathrm{LM}(12)=1.001$} \\
\hline Değişkenler & Model & Katsayı & $t$ istatistiği & Değişkenler & Model & Katsayı & t istatistiği \\
\hline LXMANA(-1) & \multirow{4}{*}{$\operatorname{ARDL}(1,1)$} & 0.106 & 1.240 & LXMESY(-1) & \multirow{4}{*}{$\operatorname{ARDL}(1,1)$} & -0.005 & -0.061 \\
\hline LBONC & & 1.563 & $4.241^{a}$ & LBONC & & 1.610 & $4.452^{\mathrm{a}}$ \\
\hline LBONC (-1) & & -1.525 & $-4.235^{a}$ & LBONC (-1) & & -1.501 & $-4.424^{\mathrm{a}}$ \\
\hline c & & -0.220 & -0.646 & c & & -0.604 & -1.957 \\
\hline \multicolumn{4}{|c|}{$R^{2}=0.169 \quad$ White $=1,033 \quad L M(1)=0.104 \quad L M(12)=0.973$} & \multicolumn{4}{|c|}{$\mathrm{R}^{2}=0.305$ White $=1.085 \mathrm{LM}(1)=0.101 \mathrm{LM}(12)=0,812$} \\
\hline Değişkenler & Model & Katsayı & $t$ istatistiği & Değişkenler & Model & Katsayı & t istatistiği \\
\hline LXULAS(-1) & \multirow{5}{*}{$\operatorname{ARDL}(4,1)$} & 0.076 & 0.748 & LXUTEK(-1) & \multirow{5}{*}{$\operatorname{ARDL}(1,4)$} & -0.032 & -0.333 \\
\hline LXULAS(-2) & & 0.087 & 0.938 & LBONC & & 0.469 & $2.293^{b}$ \\
\hline LXULAS(-3) & & 0.080 & 0.866 & LBONC (-1) & & -0.460 & -1.344 \\
\hline LXULAS(-4) & & 0.194 & $2.129^{b}$ & LBONC (-2) & & 0.165 & 0.457 \\
\hline LBONC & & 0.344 & 1.451 & LBONC (-3) & & 0.211 & 0.619 \\
\hline
\end{tabular}




\begin{tabular}{|c|c|c|c|c|c|c|c|}
\hline LBONC (-1) & & -0.511 & $-2.135^{b}$ & LBONC (-4) & & -0.449 & $-2.290^{b}$ \\
\hline c & & 0.778 & $2.340^{b}$ & c & & 0.312 & 1.088 \\
\hline \multicolumn{4}{|c|}{$\mathrm{R}^{2}=0.164$ White $=0.455 \quad \mathrm{LM}(1)=0.606$} & \multicolumn{4}{|c|}{$R^{2}=0.164$ White $=1.101 \mathrm{LM}(1)=0.218 \mathrm{LM}(12)=1,080$} \\
\hline Değişkenler & Model & Katsayı & $t$ istatistiği & Değişkenler & Model & Katsayı & $\mathrm{t}$ istatistiği \\
\hline LXTRZM(-1) & \multirow{5}{*}{$\operatorname{ARDL}(2,1)$} & -0.058 & -0.661 & LXGMYO(-1) & \multirow{5}{*}{$\operatorname{ARDL}(2,1)$} & 0.028 & 0.323 \\
\hline LXTRZM(-2) & & -0.183 & $-2.111^{b}$ & LXGMYO (-2) & & -0.159 & -1.883 \\
\hline LBONC & & 1.562 & $4.757^{\mathrm{a}}$ & LBONC & & 1.084 & $5.421^{\mathrm{a}}$ \\
\hline LBONC (-1) & & -1.511 & $-4.749^{a}$ & $\operatorname{LBONC}(-1)$ & & -1.08 & $-5.396^{a}$ \\
\hline c & & -0.309 & -0.875 & c & & -0.574 & -1.771 \\
\hline \multicolumn{4}{|c|}{$\mathrm{R}^{2}=0.05 \quad$ White $=0.528 \quad \mathrm{LM}(1)$} & \multicolumn{4}{|c|}{$R^{2}=0.266$ White $=1.145 \mathrm{LM}(1)=0.416 \mathrm{LM}(12)=1.211$} \\
\hline Değişkenler & Model & Katsayı & $t$ istatistiği & Değişkenler & Model & Katsayı & t istatistiği \\
\hline LXBANK(-1) & \multirow{4}{*}{$\operatorname{ARDL}(1,1)$} & -0.052 & -0.600 & LXSGRT(-1) & \multirow{4}{*}{$\operatorname{ARDL}(1,1)$} & -0.039 & -0.457 \\
\hline LBONC & & 1.729 & $4.394^{\mathrm{a}}$ & LBONC & & 1.226 & $4.327^{\mathrm{a}}$ \\
\hline $\operatorname{LBONC}(-1)$ & & -1.711 & $-4.396^{\mathrm{a}}$ & $\operatorname{LBONC}(-1)$ & & -1.158 & $-4.308^{\mathrm{a}}$ \\
\hline c & & -0.120 & -0.361 & c & & -0.383 & -1.061 \\
\hline \multicolumn{4}{|c|}{$\mathrm{R}^{2}=0.138$ White $=0.469 \mathrm{LM}(1)=0.368$} & \multicolumn{4}{|c|}{$\mathrm{R}^{2}=0.137$ White $=0.595 \mathrm{LM}(1)=0.141 \mathrm{LM}(12)=0.994$} \\
\hline
\end{tabular}

\subsubsection{Uzun Dönemli ilişski}

Tablo 6'da ise ARDL modelleri tahmin sonuçlarına göre hesaplanan uzun dönem katsayıları gösterilmiştir. Buna göre sadece XUTEK ve XGMYO ile BONC arasındaki uzun dönem katsayısı istatistiksel açıdan anlamlı ve pozitif bulunmuştur. Diğer modellerdeki uzun dönem katsayıları ise istatistiksel açıdan anlamsızdır.

Tablo 6: ARDL Modellerinden Elde Edilen Uzun Dönem Katsayıları

\begin{tabular}{|c|c|c|c|c|c|}
\hline Değişkenler & Katsayı & Değişkenler & Katsayı & Değişkenler & Katsayı \\
\hline \multicolumn{2}{|c|}{ ARDL $(1,1)$ BIST Sınai } & \multicolumn{2}{|c|}{ ARDL $(4,1)$ BIST Ulaştırma } & \multicolumn{2}{|c|}{ ARDL $(1,1)$ BIST Sigorta } \\
\hline LBONC & 0.044 & LBONC & -0.019 & LBONC & 0.065 \\
\hline C & -0.252 & C & 0.089 & C & -0.368 \\
\hline Değişkenler & Katsayı & Değişkenler & Katsayı & Değişkenler & Katsayı \\
\hline \multicolumn{2}{|c|}{ ARDL $(1,1)$ BIST Tekstil } & \multicolumn{2}{|c|}{ ARDL $(2,1)$ BIST Turizm } & \multicolumn{2}{|c|}{ ARDL $(1,1)$ BIST Metal Eşya } \\
\hline LBONC & 0.036 & LBONC & 0.041 & LBONC & 0.107 \\
\hline $\mathrm{C}$ & -0.212 & $\mathrm{C}$ & -0.249 & $\mathrm{C}$ & -0.600 \\
\hline Değişkenler & Katsayı & Değişkenler & Katsayı & Değişkenler & Katsayı \\
\hline \multicolumn{2}{|c|}{ ARDL $(1,1)$ BIST Kağıt } & \multicolumn{2}{|c|}{ ARDL $(1,1)$ BIST Banka } & \multicolumn{2}{|c|}{ ARDL $(2,1)$ BIST GMYO } \\
\hline LBONC & 0.067 & LBONC & 0.017 & LBONC & $0.090^{c}$ \\
\hline $\mathrm{C}$ & -0.377 & $\mathrm{C}$ & -0.114 & $\mathrm{C}$ & $-0.508^{c}$ \\
\hline Değişkenler & Katsayı & Değişkenler & Katsayı & Değişkenler & Katsayı \\
\hline \multicolumn{2}{|c|}{ ARDL $(1,1)$ BIST Kimya } & \multicolumn{2}{|c|}{ ARDL $(1,1)$ BIST Metal Ana } & \multicolumn{2}{|c|}{ ARDL $(1,4)$ BIST Teknoloji } \\
\hline LBONC & 0.055 & LBONC & 0.042 & LBONC & $0.126^{b}$ \\
\hline c & -0.309 & C & -0.246 & C & $-0.688^{b}$ \\
\hline
\end{tabular}

ve ${ }^{\mathrm{c}} \% 5$ ve \%10 anlamlılık düzeyini göstermektedir.

ARDL modellerinden uzun döneme ait katsayılar elde edildikten sonra kısa dönem tahminine geçilmiştir. Burada hata düzeltme modeli katsayının negatif ve istatistiki olarak anlamlı çıkması beklenmektedir.

\subsubsection{Kısa Dönemli illişki}

Tablo 7'de BONC ile BIST sektör endeksleri arasındaki kısa dönem ilişkiyi gösteren ARDL modellerine dayalı hata düzeltme modeli sonuçları gösterilmiştir. Buna göre çalışmada yer alan tüm sektör endeksleri ile BONC arasındaki kısa dönem ilişkiyi gösteren hata düzeltme katsayısı negatif ve aynı zamanda istatistiksel olarak anlamlı bulunmuştur. Bu durum BONC ile Borsa İstanbul sektör endeksleri arasında kısa dönem ilişki olduğunu göstermektedir. İlaveten BONC'taki artışın tüm sektör endekslerini kısa dönemde pozitif yönde etkilediği belirlenmiştir. 
Tablo 7: ARDL Modellerine Dayalı Hata Düzeltme Modeli Sonuçları

\begin{tabular}{|c|c|c|c|c|c|c|c|}
\hline Değişkenler & XUSIN & Katsayı & $t$ istatistiği & Değişkenler & XTEKS & Katsayı & $\mathrm{t}$ istatistiği \\
\hline$\triangle \mathrm{LBONC}$ & \multirow[t]{2}{*}{$\operatorname{ARDL}(1,1)$} & 1.328 & $7.068^{\mathrm{a}}$ & $\triangle \mathrm{LBONC}$ & \multirow[t]{2}{*}{$\operatorname{ARDL}(1,1)$} & 1.140 & $5.561^{a}$ \\
\hline $\mathrm{ECM}(-1)$ & & -0.950 & $-10.321^{\mathrm{a}}$ & $\mathrm{ECM}(-1)$ & & -0.965 & $-11.082^{\mathrm{a}}$ \\
\hline Değişkenler & XKAGT & Katsayı & $\mathrm{t}$ istatistiğ $\mathrm{i}$ & Değişkenler & XKMYA & Katsayı & $\mathrm{t}$ istatistiği \\
\hline$\triangle \mathrm{LBONC}(-1)$ & \multirow[t]{2}{*}{$\operatorname{ARDL}(1,1)$} & 1.065 & $5.349^{a}$ & $\triangle \mathrm{LBONC}$ & \multirow[t]{2}{*}{ ARDL(1,1) } & 1.391 & $6.352^{a}$ \\
\hline $\mathrm{ECM}(-1)$ & & -0.956 & $-10.351^{\mathrm{a}}$ & $\mathrm{ECM}(-1)$ & & -0.984 & $-10.582^{\mathrm{a}}$ \\
\hline Değişkenler & XMANA & Katsayı & $t$ istatistiği & Değişkenler & XMESY & Katsayı & t istatistiği \\
\hline$\triangle \mathrm{LBONC}$ & \multirow[t]{2}{*}{$\operatorname{ARDL}(1,1)$} & 1.563 & $3.202^{\mathrm{a}}$ & $\triangle \mathrm{LBONC}$ & \multirow[t]{2}{*}{$\operatorname{ARDL}(1,1)$} & 0.910 & $4.602^{a}$ \\
\hline $\mathrm{ECM}(-1)$ & & -0.893 & $-7.467^{a}$ & $\mathrm{ECM}(-1)$ & & -0.905 & $-6.949^{a}$ \\
\hline Değişkenler & XELKT & Katsayı & $t$ istatistiği & Değişkenler & XUTEK & Katsayı & $\mathrm{t}$ istatistiği \\
\hline$\triangle \mathrm{LBONC}$ & \multirow[t]{2}{*}{$\operatorname{ARDL}(1,1)$} & 0.661 & $3.230^{\mathrm{a}}$ & $\triangle \mathrm{LBONC}$ & \multirow[t]{2}{*}{$\operatorname{ARDL}(1,4)$} & 1.040 & $5.480^{\mathrm{a}}$ \\
\hline $\mathrm{ECM}(-1)$ & & -0.901 & $-4.464^{a}$ & $\mathrm{ECM}(-1)$ & & -0.973 & $-9.264^{a}$ \\
\hline Değişkenler & XTRZM & Katsayı & $t$ istatistiği & Değişkenler & XGMYO & Katsayı & $\mathrm{t}$ istatistiği \\
\hline$\Delta$ LXTRZM(-1) & \multirow[t]{3}{*}{$\operatorname{ARDL}(2,1)$} & 0.183 & $2.129^{b}$ & $\Delta$ LXGMYO(-1) & \multirow[t]{3}{*}{$\operatorname{ARDL}(2,1)$} & 0.159 & $1.902^{b}$ \\
\hline$\triangle \mathrm{LBONC}$ & & 1.062 & $5.710^{\mathrm{a}}$ & $\triangle \mathrm{LBONC}$ & & 0.984 & $4.364^{\mathrm{a}}$ \\
\hline $\mathrm{ECM}(-1)$ & & -0.942 & $-8.893^{a}$ & $\mathrm{ECM}(-1)$ & & -0.930 & $-6.743^{\mathrm{a}}$ \\
\hline Değişkenler & XBANK & Katsayı & $\mathrm{t}$ istatistiği & Değişkenler & XSGRT & Katsayı & $\mathrm{t}$ istatistiği \\
\hline$\triangle \mathrm{LBONC}$ & \multirow[t]{2}{*}{$\operatorname{ARDL}(1,1)$} & 0.929 & $4.420^{\mathrm{a}}$ & $\triangle \mathrm{LBONC}$ & \multirow[t]{2}{*}{$\operatorname{ARDL}(1,1)$} & 0.926 & $4.343^{a}$ \\
\hline $\mathrm{ECM}(-1)$ & & -0.952 & $-7.179^{\mathrm{a}}$ & $\mathrm{ECM}(-1)$ & & -0.939 & $-6.197^{\mathrm{a}}$ \\
\hline
\end{tabular}

ve ${ }^{\mathrm{b}} \% 1$ ve $\% 5$ anlamlılık düzeyini göstermektedir.

Değişkenler arasındaki nedensellik ilişkisi ise Toda-Yamamoto nedensellik testi ile test edilmiştir. Tablo 8'de TodaYamamoto nedensellik testine ilişkin elde edilen bulgular sunulmuştur. Tabloya göre XMANA endeksi ile BONC arasında çift yönlü, BONC'tan XUSIN, XKAGT, XKMYA, XMESY, XULAS, XTRZM, XTEKS, XBANK, XSGRT, XGMYO ve XUTEK endekslerine doğru ise tek yönlü nedensellik olduğu tespit edilmiştir.

Tablo 8: Toda-Yamamoto Nedensellik Testi Sonuçları

\begin{tabular}{|c|c|c|c|}
\hline Nedenselliğin Yönü & F ist. & Nedenselliğin Yönü & F ist. \\
\hline $\begin{array}{l}\text { XUSIN } \longrightarrow \text { BONC } \\
\text { BONC } \longrightarrow \text { XUSIN }\end{array}$ & $\begin{array}{l}4.212 \\
35.77^{\mathrm{a}}\end{array}$ & $\begin{array}{l}\text { XTRZM } \longrightarrow \text { BONC } \\
\text { BONC } \longrightarrow \text { XTRZM }\end{array}$ & $\begin{array}{r}1.140 \\
18.161^{\mathrm{a}}\end{array}$ \\
\hline $\begin{array}{l}\text { XKAGT } \longrightarrow \text { BONC } \\
\text { BONC } \longrightarrow \text { XKAGT }\end{array}$ & $\begin{array}{l}0.552 \\
22.66^{\mathrm{a}}\end{array}$ & $\begin{array}{l}\text { XTEKS } \longrightarrow \text { BONC } \\
\text { BONC } \longrightarrow \text { XTEKS }\end{array}$ & $\begin{array}{c}0.552 \\
22.666^{\mathrm{a}}\end{array}$ \\
\hline $\begin{array}{l}\text { XKMYA } \longrightarrow \text { BONC } \\
\text { BONC } \longrightarrow \text { XKMYA }\end{array}$ & $\begin{array}{l}3.734 \\
27.80^{\mathrm{a}}\end{array}$ & $\begin{array}{l}\text { XBANK } \longrightarrow \text { BONC } \\
\text { BONC } \longrightarrow \text { XBANK }\end{array}$ & $\begin{array}{r}1.820 \\
21.467^{\mathrm{a}} \\
\end{array}$ \\
\hline $\begin{array}{l}\text { XMANA } \longrightarrow \text { BONC } \\
\text { BONC } \longrightarrow \text { XMANA }\end{array}$ & $\begin{array}{l}9,976^{\mathrm{b}} \\
22.171^{\mathrm{a}}\end{array}$ & $\begin{array}{l}\text { XSGRT } \longrightarrow \text { BONC } \\
\text { BONC } \longrightarrow \text { XSGRT }\end{array}$ & $\begin{array}{r}5.813 \\
22.082^{\mathrm{a}} \\
\end{array}$ \\
\hline $\begin{array}{l}\mathrm{XMESY} \longrightarrow \mathrm{BONC} \\
\mathrm{BONC} \longrightarrow \mathrm{XMESY}\end{array}$ & $\begin{array}{c}2.173 \\
47.745^{a}\end{array}$ & $\begin{array}{l}\mathrm{XGMYO} \longrightarrow \mathrm{BONC} \\
\mathrm{BONC} \longrightarrow \mathrm{XGMYO}\end{array}$ & $\begin{array}{r}1.578 \\
28.884^{\mathrm{a}}\end{array}$ \\
\hline $\begin{array}{l}\text { XULAS } \longrightarrow \text { BONC } \\
\text { BONC } \longrightarrow \text { XULAS }\end{array}$ & $\begin{array}{l}0.366 \\
7.195^{c}\end{array}$ & $\begin{array}{l}\text { XUTEK } \longrightarrow \text { BONC } \\
\text { BONC } \longrightarrow \text { XUTEK }\end{array}$ & $\begin{array}{r}1.260 \\
17.785^{\mathrm{a}}\end{array}$ \\
\hline
\end{tabular}

\section{SONUÇ}

Ekonomik faaliyetlerdeki dalgalanmaların önceden tahmin edilebilmesi, özellikle de son yıllarda yaşanan krizlerden sonra daha da önemli hale gelmiştir. Bu tür bir tahminin yapılabilmesi için ise ekonomik ve finansal göstergelere ihtiyaç duyulmaktadır. TCMB’nin yayınladığı Bileşik Öncü Göstergeler Endeksi (BONC) makroekonomide yaşanılan daralma veya genişlemelerin önceden tahmini açısından yararlıdır. Böylelikle varlık fiyatlarında gelecekte oluşabilecek hareketler öngörülebilir.

Bu çalışmada 2006:01-2016:10 dönemi için bileşik öncü göstergeler ile Borsa İstanbul sektör endeksleri arasındaki kısa ve uzun dönemli ilişkiler incelenmiştir. Çalışmada öncelikle değişkenlerin durağan olduğu düzeyler ADF ve PP yöntemleri ile araştırılmış ve sektör endekslerinin düzeyde, BONC'un ise 1. farkında durağan olduğu belirlenmiştir. Ardından Sınır testi yardımıyla çalışmada yer alan her bir sektör endeksi ile BONC 
arasındaki uzun dönem ilişki test edilmiş ve yapılan analizler sonucunda her bir sektör endeksinin BONC ile uzun dönemde ilişkili olduğu tespit edilmiştir.

Ardından ARDL modelleri yardımıyla uzun ve kısa dönem katsayıları araştııımıştır. Uzun dönemde BONC'ta meydana gelen pozitif değişimlerin, XUTEK ve XGMYO endekslerini istatistiksel açıdan anlamlı ve pozitif yönde etkilediği belirlenmiştir. Ardından kısa dönemli ilişkiyi incelemek için ARDL modellerine dayalı hata düzeltme modeli tahmin edilmiştir. Elde edilen sonuçlar çalışmada yer alan tüm sektör endeksleri ile BONC arasındaki kısa dönemli ilişki olduğunu göstermiştir. İlaveten BONC'taki artışın tüm sektör endekslerini kısa dönemde pozitif yönde etkilediği belirlenmiştir.

Ardından değişkenler arasındaki nedensellik ilişkisi Toda ve Yamamoto (1995) testi ile araştırılmıştır. Elde edilen bulgular XMANA endeksleri ile BONC arasında çift yönlü, BONC'tan XUSIN, XKAGT, XKMYA, XMESY, XULAS, XTRZM, XTEKS, XBANK, XSGRT, XGMYO ve XUTEK endekslerine doğru ise tek yönlü nedensellik ilişkisinin olduğu tespit edilmiştir.

Bileşik öncü göstergeler endeksi ve sektör endeksleri arasındaki ilişkilere ait bu sonuçlar, yatırımcıların hisse senetlerine yatırım yaparken sektör ayırt etmeksizin bileşik öncü göstergeler endeksini dikkate aldığını ve BONC'un hisse senedi fiyatları için önemli bir gösterge olduğunu ortaya koymaktadır.

Elde edilen bu sonuçlar hisse senedi endekslerine yatırım yapmayı düşünen potansiyel yatırımcıların hisse senedi piyasalardaki değişimlerin belirleyicisi olarak BONC'a dikkat etmeleri gerektiğini göstermiştir. ilerleyen çalışmalarda farkı ülkeler veya farklı endeksler dikkate alınarak literatüre katkı sağlanabilir.

\section{KAYNAKLAR}

Demirhan, A. A., (2014). Ekonomik faaliyet için bileşik öncü göstergeler endeksi'nde (MBÖNCÜ-SÜE) yöntemsel değişim. TCMB Ekonomi Notları, s. 1-9.

Gülhan, Ü., Kaya A., Güngör, B., (2012). Bileşik öncü göstergeler ve borsa endeksi ilişkisinin uluslararasi boyutta incelenmesine yönelik bir araştırma. Dokuz Eylül Üniversitesi İktisadi ve İdari Bilimler Fakültesi Dergisi, vol. 27, no. 3, s. 1-27.

Hacıhasanoğlu, E. ve Soytaş, U., (2011). Bileşik öncü göstergeler ve sektörel endeksler arasindaki ilişki. Dokuz Eylül Üniversitesi İktisadi ve İari Bilimler Fakültesi Dergisi, vol. 26, no. 1, s. 79-91.

OECD System of Composite Leading Indicators (2012). http://www.oecd.org/std/leading-indicators/41629509.Pdf, 10.09.2016.

Pesaran, M. H., (1997). The role of economic theory in modelling the long run. The Economic Journal, vol. 107 no. 440, p. $178-191$.

Pesaran, M. H., Y. Shin, Smith, R. J., (2001). Bounds testing approaches to the analysis of level relationships. Journal of Applied Econometrics vol. 16, p. 289-326.

Phillips, P. C., Perron, P., (1988). Testing for a unit root in time series regression, Biometrika, vol. 75, no. 2, p. 335-346.

Sharma, G. D., Mahendru, M., (2010). Impact of macro-economic variables on stock prices in India. Global Journal of Management and Business Research, vol. 10, no. 7, p. 1-18.

Toda, H. Y., Yamamoto, T., (1995). Statistical inference in vector auto regressions with possibly integrated process. Journal of Econometrics, vol. 66 , p. 225-250.

Topcu, E., (2014). Bileşik öncü göstergeler ile hisse senedi piyasalari arasindaki ilişki: Türkiye örneği. AKÜ iiBF Dergisi, vol. 16, no. 1, p. 167176.

Topcu, M., Ünlü, U., (2013). Do investors consider composite leading indicators? Time series evidence from emerging countries. Theoretical and Applied Economics, vol. 20, no. 9, p. 51-62. 